\title{
AVALIAÇÃO DA ORGANIZAÇÃO DO ESPAÇO ESCOLAR NA PERCEPÇÃO DOCENTE: UM ESTUDO REALIZADO EM ESCOLAS DA REDE PÚBLICA MUNICIPAL DE FORTALEZA/CE
}

http://dx.doi.org/10.5902/2318133824966

\author{
Marcos Antonio Martins Lima \\ Universidade Federal do Ceará, Brasil.
}

Denize de Melo Silva

Município de Fortaleza, Brasil.

\author{
Ana Paula Vasconcelos de Oliveira Tahim \\ Faculdade Cearense, Brasil.
}

\begin{abstract}
Resumo
Neste texto busca-se apresentar os resultados de uma avaliação acerca da gestão escolar com base na percepção dos docentes oriundos das escolas da rede pública municipal de Fortaleza, Ceará. A metodologia da pesquisa compreende as etapas de investigação e análise do objeto. $A$ escolha das instituições foi feita com base no Índice de Desempenho Escolar Alfa (0-10) correspondente ao período de 2012 e 2014. A análise qualitativa foi realizada com base no Atlas.ti7 com vistas a entender os discursos provenientes dos docentes para a compreensão acerca da organização do espaço escolar e do papel desempenhado pelo gestor. Verificou-se que o trabalho atrelado à formação docente deve considerar os anseios dos docentes e discentes, além do contexto em que as práticas são conduzidas nas escolas.

Palavras-chave: organização escolar, percepção docente, avaliação educacional.
\end{abstract}

\section{EVALUATION OF SCHOOL AREA ORGANIZATION IN TEACHING PERCEPTION: A STUDY CONDUCTED IN SCHOOLS OF THE MUNICIPAL PUBLIC NETWORK OF FORTALEZA-CE}

\section{Abstract}

This study aims to make an evaluation about school management based on the perception of teachers from schools of the municipal public network in Fortaleza, Ceará. The research methodology comprises the stages of investigation and analysis of the object; however, the choice for the institutions was based on the Alpha School Performance Index (0-10) corresponding to the period of 2012 and 2014. The qualitative analysis was carried out based on Atlas.ti7 in order to understand the discourses derived from the speech of the teachers, to understand the organization of the school area and the role played by the school manager. It was verified that the work linked to teacher training should consider the wishes of teachers and students, in addition to the context in which practices are conducted in schools.

Key-words: school organization, teacher perception, educational evaluation. 


\section{Introdução}

bserva-se que a organização do espaço é fundamental para a promoção de saberes e práticas que integrem a comunidade educativa para a superação progressiva dos desafios específicos de cada realidade observada na escola. Diante desse contexto o núcleo gestor desempenha importante papel na organização escolar e na ampliação do diálogo e na participação dos agentes que integram a dinâmica escolar. Neste sentido, neste trabalho se busca a realizar uma avaliação da gestão escolar com base na percepção de dez docentes da rede pública municipal de Fortaleza, Ceará.

Essa avaliação servirá como base para a compreensão acerca das ações desempenhadas pelo núcleo gestor, tendo em vista a necessidade de integração dos docentes aos processos de tomadas de decisão na escola.

Foram entrevistados dez docentes que atuam diretamente na rede pública municipal de Fortaleza-CE. A triagem dos sujeitos da pesquisa foi realizada levando em conta 0 Índice de Desempenho Escolar Alfa (0-10) correspondente ao período de 2012 e 2014. A coleta de dados foi amparada na pesquisa de campo e na aplicação de roteiro com oito assertivas condizentes ao papel desempenhado pelo núcleo gestor nas instituições de ensino.

A análise qualitativa foi realizada com base no Atlas.ti7, a fim de entender as manifestações dos docentes para a compreensão acerca da organização do espaço escolar e do papel desempenhado pelo gestor.

Verificou-se que o trabalho atrelado à formação docente deve, pois, considerar os anseios dos docentes e discentes, além do contexto em que as práticas são conduzidas nas escolas. Essa avaliação apresenta-se como relevante e contínua, visando à realidade e necessidades dos estudantes e à dialogicidade nos encaminhamentos gerados e praticados na escola.

\section{Evolução histórico-conceitual da gestão educacional no Brasil}

Nesta seção discute-se sobre os autores e seus postulados que respaldam o debate teórico para que se possa compreender melhor o assunto deste trabalho científico. A fim de estabelecer sentido ao aprofundamento realizado, percebem-se que as nuances que permeiam as práticas educacionais e o sistema de educação são necessárias, uma vez que por intermédio de tais compreensões passa-se a aprofundar o olhar sobre a diversidade de contextos e conceitos ao modo como a gestão escolar consolidou-se no Brasil.

Assim, cabe ressaltar a gênese dos termos que circundam essa temática em estudo com vistas a articular as matrizes que são essenciais para o gerenciamento acerca do pensamento e ações práticas observadas hoje que revelam traços passados de transformação da sociedade e dos indivíduos que a compõem.

Segundo Saviani (2010) deve-se refletir sobre a denominação sistema, de sorte que se estabeleçam proposições claras e objetivas sobre os produtos gerados da ação do indivíduo a partir da ótica da sua análise.

Conforme o autor, nesse processo de transformação, o homem, como sujeito do processo de transformação, acaba exercendo sua influência sobre o meio, ou seja, tornase o interlocutor ao exercer ação sobre o mundo em suas dimensões. Sob esse enfoque 
sistemático o ser assume diversas perspectivas de atuação consciente. Essa condição atrela-se ao modo como realiza as atividades e estabelece sentido para com as mesmas e sua função enquadra-se no papel simbólico que assume. $O$ conceito de sistema intercala-se à intencionalidade das ações, à variedade, às coerências interna e externa das práticas relacionadas ao contexto em que evidenciam-se tais ações.

A partir do ideal de assegurar o direito à educação para todos pretende-se estabelecer o direito universal à escola. A essa suposição sistemática cabe a reflexão dos aspectos históricos que nortearam essa proposição. Os anseios da classe burguesa e moderna, norteados por intermédio dos ideais de desenvolvimento e transformação, estavam presentes desde o sistema feudal e a partir do desenvolvimento do comércio e a necessidade de uma mão de obra qualificada a fim de aumentar a produtividade das organizações fizeram-se necessárias. Aliado a esse contexto, cabe relacionar 0 deslocamento do campo para a cidade, de modo a corroborar o processo produtivo e o desenvolvimento da indústria, provocando mudanças no eixo do processo cultural (Saviani, 2010).

A consolidação dos estados-nação a partir do século 19, segundo o autor, contribuiu para a organização dos sistemas nacionais de educação. O modelo jesuítico implantado e sistematizado por Dom João III direcionou a manutenção das aulas organizadas pelos jesuítas, o que foi mantido pelo então marquês de Pombal.

Em todas as cidades, vilas e lugares mais populosos, haverá as escolas de primeiras letras que forem necessárias. Mas essa letra permaneceu morta e 0 ato adicional à Constituição do Império, promulgado em 1834, dispôs o ensino primário sob a jurisdição das províncias, desobrigando o Estado nacional de cuidar desse nível de ensino. Mas as províncias não estavam equipadas financeira nem tecnicamente para promover a difusão do ensino (Saviani, 2010).

Entretanto, verificou-se a estagnação do ensino por meio das altas taxas de analfabetismo da população. $O$ termo referente à organização articula-se com o modo como se ordena e se constitui um sistema. Essa organização da educação faz-se com a participação das esferas administrativas, ou seja, pela União, pelos Estados, pelos municípios e pelo Distrito Federal. Os dispositivos anteriormente mencionados estão presentes nos artigos 17, 18 e 19 da Lei de Diretrizes e Bases de 1996. Conforme os referidos artigos a educação escolar no Brasil está organizada em três esferas administrativas: União, Estados, Municípios e Distrito Federal (Libâneo; Oliveira; Toschi, 2012).

Diante do exposto atrelam-se a cada sistema determinada função e importância no tangente à organização do ensino. Para tanto, faz-se necessário compreender as variáveis históricas presentes na gestão educacional, buscando refletir acerca das práticas educacionais ocorridas na atualidade e nas relações de aprendizagem desenvolvidas na escola. De acordo com a Constituição e a LDB, a gestão da educação nacional se expressa através da organização dos sistemas de ensino federal, estadual e municipal; das incumbências da União, dos estados e dos municípios; das diferentes formas de articulação entre as instâncias normativas, deliberativas e executivas do setor educacional; e da oferta de educação escolar pelo setor público e privado (Vieira, 2007).

A fermentação liberalista que precedeu à proclamação da independência constitui-se como feito de minorias exaltadas e sua repercussão limitada ao povo: "A organização e a estrutura da educação no Brasil deram-se em decorrência das leis n. 4.024, de 1961, 
denominada a primeira lei de diretrizes e bases da educação (LDB), e n. 5.540, de 1968, [...] criada com o intuito de reforma do ensino superior" (Libâneo; Oliveira; Toschi, 2012, p. 328).

Segundo os autores, decorridas mais de duas décadas após a promulgação da Constituição Federal datada de 1988, caracterizada pelas mudanças de nomenclatura das terminologias das modalidades de ensino, pela noção sistêmica da escola e pela abrangência da sua ação, verificaram-se poucas mudanças na educação escolar. A vigente LDB subsidia o sistema de educação nacional, substituído pela organização da educação nacional, causando entraves para a produção coletiva articulada ao Plano Nacional da Educação que fora retirado da referida legislação.

As reformas educativas integram-se na perspectiva de compreensão da organização e da gestão presentes nas escolas. Conforme Lück (2012), nesse contexto a gestão educacional emerge para superar, dentre outros aspectos, a visão global e abrangente acerca do fenômeno educativo, promovendo a ação consciente articulada, dinâmica e participativa.

Conforme Vieira (2007),

se em tese assim se organiza a gestão educacional, na prática esta é atravessada por aqueles elementos antes referidos: as condições de implementação, que demandam disponibilidade financeira (capital e custeio), recursos humanos e outras condições materiais e imateriais. A gestão educacional também depende de circunstâncias políticas e envolve constante negociação e conflito. Uma arena propícia ao entendimento dessa dimensão diz respeito ao encaminhamento de projetos, sejam estes de autoria do Poder Executivo, ou não, e sua respectiva tramitação no âmbito do Poder Legislativo. A votação de leis de educação do presente e do passado, como a LDB de 1961 e de 1996, são exemplos de como o Congresso pode obstruir ou facilitar as expectativas de mudança (e de conservação) traduzidas em tais iniciativas. (p. 9)

Lück (2012) realiza um paralelo decorrente da compreensão de gestão educacional ligada às teorias administrativas, promovendo um aprofundamento conceitual: "A gestão do ensino supera o enfoque limitado de administração, a partir do entendimento de que os problemas educacionais são complexos" (p. 23).

Dessa forma destacam-se a visão ampla e a ação articulada, dinâmica e participativa para a compreensão do fenômeno educativo. Diante disso, cabe, pois, visualizar as necessidades e carências observadas no centro da escola para a superação dessas lacunas por meio de orientações claras e competentes exercidas através de ligações democráticas e integradas a uma gestão educacional consciente do papel a ser desenvolvido.

A coordenação dos esforços individuais e coletivos em torno da consecução de objetivos comuns, definidos por uma política de ação e inspirados por uma filosofia orientadora por todos partilhada, tem um sentido mais amplo do que o de ação administrativa, que, por sua vez, passa a ser um dos elementos da gestão (Portela; Atta, 2007, p. 16). Nesse contexto, caberá à gestão educacional o estabelecimento de estratégias de organização para além do caráter puramente administrativo, entretanto deverá buscar o enlace dos elementos que favoreçam a prática reflexiva integrada aos aspectos sociais, culturais e pedagógicos presentes no contexto escolar. 
Na LDB de 1996 atenta-se para o registro da organização da educação, dentre os ofícios destacados pela União no artigo 9‥ Para Demo (1997), cabe assegurar a análise e disseminação das informações sobre educação, admitindo as qualidades dessas instituições e sua contribuição para o progresso das práticas educativas. Segundo o autor a organização dos sistemas escolares acontece por meio da concepção centralizadora por parte do governo federal. Nesse caso consideram-se as atribuições e incumbências que estabelecem as conotações e concepções de gestão democrática no estabelecimento de ligações entre as instituições, órgãos educacionais e sistemas de ensino.

Nesse contexto, cabe a sistematização de algumas considerações sobre a referida legislação e as práticas adjacentes para a organização do ensino. Numa análise mais detalhada captamos ainda outros problemas, como a dubiedade de sentidos passíveis de qualidade de validade em alguns pontos e com a duplicação de prioridades em outros, o que nos deixa em dúvida quanto à priorização real de uma coisa ou outra, de acordo com a interpretação que se dê à lei. O perigo maior, entretanto, neste caso, é o da negação da própria ideia de prioridade. Se tudo é prioritário, nada o é (Oliveira; Alves; Villardi, 1997).

Nessa perspectiva observa-se que, ao disseminar autonomia aos municípios na organização e distribuição de tarefas e ofícios, a referida legislação proporciona aspectos legais e políticos, estabelecendo a denominada democratização das especificidades e contextos diferenciados e viabilizando o exercício do poder aos sistemas de ensino: "Qualitativamente, as incumbências da União embasam-se em: organizar, manter e desenvolver os órgãos e instituições oficiais dos seus sistemas de ensino, integrando-os às políticas e planos educacionais da União e dos Estados" (Oliveira; Alves; Villardi, 1997, p. 70).

\section{Gestão educacional e avaliação: considerações terminológicas essenciais}

A gestão escolar constitui-se como uma dimensão importante da educação uma vez que, por meio dela, observam-se a escola e os problemas educacionais globalmente e se busca abranger, pela visão estratégica e de conjunto, as ações e os problemas que, de fato, funcionam de modo interdependente.

As transformações sociais, científicas e tecnológicas passaram a exigir da escola um novo modelo e concepção de gestão. Conforme Andrade (2004) simbolizam uma representação fidedigna na transformação da postura, enfoque didático e organização com formação e saberes inerentes à sua posição, ocasionando eficiência e eficácia na gestão da escola.

Para Lück (2000) o conceito de gestão excede o conceito de administração, por envolver a participação da comunidade nas decisões que são tomadas. Esse novo conceito de gestão excede o conceito de administração, por envolver a participação da comunidade nas decisões que são tomadas na escola.

Barroso (2001) entende que esse conceito relacionado à administração torna-se mais significativo, uma vez que se utiliza dessa forma para obter um sentido global em que a política educativa insere-se diferentemente do emprego do termo gestão escolar, referindo-se apenas à função de execução, ou seja, colocar em exercício as políticas antecipadamente acordadas e definidas. 
O termo gestão transformou-se em sinônimo de ambiente autônomo e participativo, resultando em um trabalho coletivo e compartilhado por vários segmentos que compõem a escola e, assim, buscam atingir objetivos comuns com uma colaboração responsável das partes interessadas.

Dessa forma, o papel do diretor passa a ter outras características para além da antiga função de fiscalizar e controlar, que centralizava em si as decisões. Segundo Lück (2000) transforma-se em um gestor da dinâmica social, um mobilizador, um orquestrador de atores, um articulador da diversidade para dar unidade e consistência à construção do ambiente educacional e promoção segura da formação de seus alunos.

Ressalta-se, assim, o papel do gestor na organização desse espaço a fim de ultrapassar empecilhos que interfiram significativamente na gestão do ensinoaprendizagem, de modo a refletir sobre as metodologias que integram a grade curricular de ensino nas escolas. O gestor escolar necessita de aprofundamento nas estratégias metodológicas, objetivando a mobilização das ações e sistematização dos combinados realizados na escola.

Segundo Andriola (2005, p. 97), "a produtividade refere-se ao compromisso com o trabalho, disciplina, produção sistemática. É a capacidade de contribuir, via elaboração própria, para intervenções na realidade". Busca-se um ensino de melhor qualidade, a construção de formas mais eficazes para proceder à avaliação do processo de ensinoaprendizagem.

As instituições de ensino utilizam-se da prática da avaliação para tomadas de decisões com o intuito de rever os objetivos adotados com vistas a uma melhor utilização de estratégias para superação de dificuldades durante todo o percurso. Faz-se necessário, portanto, que a avaliação da gestão constitua-se de traços definidos, considerando o contexto adjacente à própria prática educativa.

A avaliação, consoante Luckesi (2005), pode ser considerada como uma forma de ajuizamento de qualidade do objeto avaliado, fator que implica novas tomadas de posição a respeito do mesmo no sentido de refletir sobre o objeto.

Conforme Andriola (2005) é preciso mais flexibilidade perante a emissão de julgamento de valores, seja no tocante à avaliação de aprendizagem curricular, de programa ou de instituição. Nesse contexto, a avaliação desvela um conjunto de aspectos multidisciplinares que envolvem prioridades definidas ao longo do processo educativo e dos recursos disponíveis.

Ver-se-á que, na prática, a avaliação usada para orientar está longe de ser criada unicamente para esse fim. Na maioria dos sistemas a orientação situa-se entre dois modelos extremos: no primeiro, é inteiramente decidida pelo aluno ou sua família; no segundo, é inteiramente decidida pela escola (Perrenoud, 1999). Portanto, verifica-se que não há orientação educacional sem vínculo ao processo avaliativo de investigação e análise. As tomadas de decisões devem, pois, fundamentar-se em um processo contínuo, a fim de gerar o estabelecimento de ações destinadas para cada necessidade visualizada no contexto escolar. 
De acordo com Luckesi (2005), avaliar é, pois, regular e articular as informações que advêm dos instrumentos utilizados, buscando melhorias e respostas aos questionamentos propostos, aperfeiçoando a qualidade da educação, visando à transformação da sociedade comprometida com o ensino e com os anseios das instituições envolvidas no processo.

O processo de avaliação relaciona-se aos objetivos de determinadas instituições de ensino, vislumbrando uma tomada de decisão e, por conseguinte, uma reflexão sobre a realidade e os objetos de estudo em análise. A avaliação educacional deve ser uma prática coletiva, ou seja, deve envolver os atores que circundam o processo educativo e diagnosticar, por meio de análises constantes, se os objetivos traçados para cada etapa estão sendo alcançados.

O papel da avaliação nas instituições de ensino integra um processo contínuo, corroborando a gestão estratégica e de qualidade, pois fornece insumos necessários para a tomada de decisão, bem como auxilia na resolução de problemas. Destina-se aos diagnósticos e possíveis resoluções dos problemas observados nas instituições de ensino.

O processo avaliativo torna-se fator de desenvolvimento e melhoria, caso as instituições de ensino o utilizem como diagnóstico e melhoria das práticas educacionais já existentes. A partir da avaliação institucional e sua utilização no dia a dia das unidades de ensino, busca-se desvelar as etapas do processo de ensino-aprendizagem, os currículos e a gestão inseridos no contexto educacional, com o intuito de ocasionar melhorias positivas nesse contexto.

\section{Metodologia}

O lócus deste estudo constitui-se de um universo formado por seis escolas da rede pública municipal de Fortaleza. A triagem foi realizada com base no Índice de Desempenho Escolar Alfa (0-10) correspondente aos períodos de 2012 a 2014. Conforme Araújo (2016) o IDE é calculado a partir de três elementos: a proficiência da escola, a taxa de participação no Spaece-Alfa e o fator de ajuste para a universalização do aprendizado - percentual de alunos nos níveis adequados) O respectivo critério foi adotado na pesquisa com o propósito de selecionar as instituições e sua utilização faz referência às escolas pesquisadas com IDE satisfatório e IDE não satisfatório, o que foi levado a efeito unicamente para diferenciar as instituições de ensino umas das outras.

A etapa compreendeu a observação e contextualização das variáveis analisadas por meio da aplicação de roteiro com oito assertivas abertas destinadas aos dez docentes oriundos da rede pública municipal de Fortaleza, Ceará.

A análise qualitativa foi amparada na compreensão dos discursos provenientes da manifestação dos professores, buscando agregar aspectos indispensáveis relativos à compreensão acerca do trabalho desenvolvido nas escolas pesquisadas. Essa análise foi embasada por meio da adoção do programa denominado Atlas.ti7: computer - assisted qualitive data analysis software - Caqdas), respaldando essa compreensão mediante as falas dos sujeitos que constituem a comunidade educativa. As unidades hermenêuticas serviram de base para a discussão traçada, revelando especificidades presentes em cada instituição de ensino. 


\section{Resultados e discussão}

A primeira assertiva contida no instrumental fez menção aos aspectos positivos decorrentes da atuação do gestor na escola. Conforme a percepção docente analisada verificou-se que os professores sugerem diversas ações positivas no tocante ao desempenho do trabalho do gestor escolar e que o mesmo é tido como figura importante na organização do espaço escolar: "Ele se integra muito aos alunos, não fica só na sala dele. Entendeu?" (docente B2, escola B).

Os docentes das instituições com IDE satisfatório enfatizam a importância do apoio aos professores nas decisões da escola $(n=1)$ e que as opiniões dos educadores devem ser consideradas $(n=1)$, a fim de propor melhorias gradativas para a unidade escolar. $A$ preocupação com o orçamento da escola $(n=1)$ e a atenção fornecida pelo gestor na acolhida dos alunos na escola foram categorias apontadas pelos profissionais entrevistados.

O diálogo e a orientação dos discentes que favorecem uma boa gestão embasam-se nos desafios das instituições de ensino: "Uma boa gestão escolar se estabelece na unidade, direcionamento, ímpeto, consistência e coerência à ação educativa" (Lück, 2012, p. 17).

Os educadores das escolas com IDE não satisfatório afirmam que o diretor exerce gestão democrática, pois considera as opiniões dos docentes $(n=1)$. Verificou-se nas manifestações dos sujeitos entrevistados a preocupação do diretor escolar com a aprendizagem significativa dos educandos $(n=2)$. Diante disso, considera-se que a firmeza e objetividade nas decisões favorecem uma gestão integrada e participativa.

De acordo com a análise realizada com base nas categorias geradas por meio da ressignificação das unidades hermenêuticas adotadas na pesquisa, verificou-se que a gestão democrática insere-se na dinâmica escolar, ao passo que as ações são orientadas, entretanto necessitam ser fortalecidas no âmbito escolar com a participação efetiva dos docentes, discentes e comunidade escolar. $O$ conceito de gestão democrática insere-se na participação e autonomia dos sujeitos que integram a escola (Lück, 2012).

A rede de interesses, figura 1, situa as contribuições da gestão democrática para a universalização das boas práticas adotadas nas instituições e das melhorias a serem alcançadas para o bom funcionamento da escola e para a aprendizagem significativa dos educandos. 
Figura 1 -

Gestão democrática.

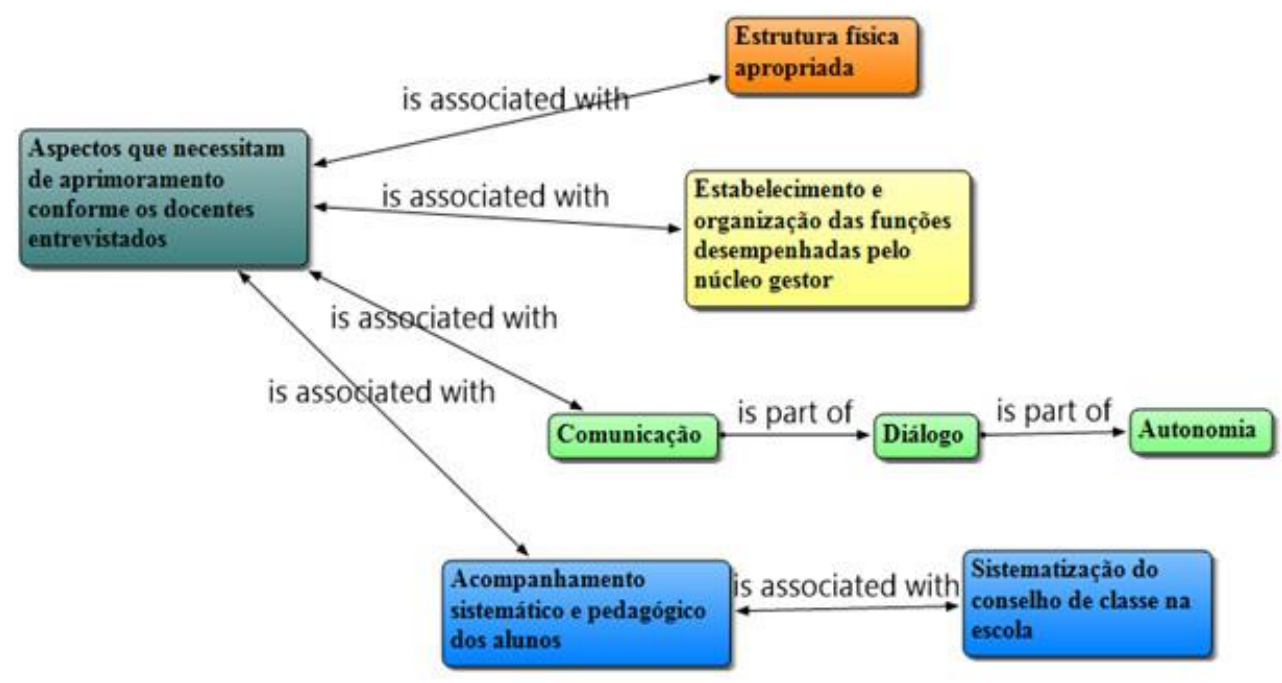

Fonte: Elaboração própria.

A segunda premissa contida no instrumental faz menção aos aspectos negativos apresentados pelo gestor escolar e ao trabalho desenvolvido na escola. Segundo a percepção docente das escolas com IDE satisfatório verificou-se que os docentes necessitam da presença do gestor na escola e que as reuniões na Secretaria Municipal da Educação e a falta de autonomia da instituição $(n=1)$, por diversas vezes, fazem com que o diretor tenha que se afastar da unidade escolar para comparecer a esses compromissos obrigatórios $(n=1)$.

Todavia, a comunicação das diretrizes estabelecidas também deve ser socializada aos docentes da instituição $(n=1)$. O diálogo deve ser componente essencial para que novas práticas sejam estabelecidas na escola com o objetivo de aprimorar o papel do professor em sala de aula e auxiliá-lo nessa construção.

Constatou-se também que os docentes necessitam que suas opiniões sejam escutadas e consideradas para novas tomadas de decisões na escola $(n=1)$. Não obstante faz-se mister que o gestor escolar considere e compreenda as necessidades do grupo em que realiza suas ações, com o objetivo de agregar valores e sugestões ao dia a dia da instituição, minimizando a inflexibilidade $(n=2)$ e centralização das tomadas de decisão na escola.

Os educadores das escolas com IDE satisfatório apontam que o desenvolvimento das ações ocorre lentamente, pois depende da organização e sistematização da Prefeitura de Fortaleza $(n=1)$. Contudo, verifica-se, segundo a percepção analisada, que há o engessamento das práticas desenvolvidas na escola pela falta de autonomia e pela rigidez das normatizações estabelecidas para as unidades de ensino: " $A$ secretaria municipal tem algumas determinações que são muito, digamos assim, como se fosse de uma maneira muito engessada de a escola não ter muita autonomia na sua gestão" (docente A2, escola A). 
Diante disso, percebe-se que se deve pensar acerca das decisões tomadas e se elas levam em consideração os contextos e a realidade em que essas instituições estão inseridas. Faz-se necessário perceber que "o reforço que se dá à gestão visa, em última instância, a melhorias das ações e processos educacionais, voltados para a melhoria da aprendizagem" (Lück, 2012, p. 17).

Conforme a percepção dos docentes com IDE não satisfatório, observou-se também o engessamento $(n=2)$ e a falta de autonomia $(n=1)$ dos profissionais das instituições em decorrência do cumprimento de normatizações que não levam em consideração o contexto e a realidade adjacentes às escolas $(n=1)$. $O$ orçamento fornecido constitui-se como insuficiente e limitado $(n=1)$, pois não supre as necessidades mínimas da estrutura da instituição de ensino $(n=1)$.

Diante da análise realizada, segundo os docentes das escolas com IDE satisfatório, verificou-se que a autonomia $(n=1)$, a comunicação $(n=1)$ e o acompanhamento sistemático $(n=2)$ dos alunos são aspectos que devem ser aprimorados, tendo em vista que as instituições necessitam fornecer acompanhamento processual do desenvolvimento de cada aprendiz na escola, estabelecendo os desafios preconizados para a sua aprendizagem e a conversa aberta com os docentes da instituição sobre acertos e dificuldades no processo educativo, aspecto substancial para aprimoramentos da relação processual de ensino-aprendizagem, conforme a fala do docente B2 da escola B. Nesse sentido, cabe trazer o relato literal de um professor: "A questão das coordenadoras com os alunos para fazer um trabalho de acompanhamento, pois não tem também" (docente B1, escola B).

Para tanto, observa-se que as funções desenvolvidas pelo núcleo gestor devem organizar-se de modo que os colaboradores das instituições de ensino $(n=1)$ atentem para o devido exercício de cada sujeito e sua relevância para esse espaço construtivo e participativo de aprendizagem desenvolvido na escola.

Os docentes das instituições que não apresentam IDE satisfatório denotam que a estrutura física $(n=2)$ escolar necessita de aprimoramento, objetivando o estabelecimento de um espaço acolhedor para a aprendizagem. Verifica-se também que os espaços da escola também precisam ser aproveitados, para tanto se necessita de flexibilização dos orçamentos destinados aos gestores do município para que efetuem tais mudanças e realizem a compra de equipamentos e a execução das obras.

Todavia, a gestão democrática propõe o estabelecimento de ações eficazes para a participação efetiva dos profissionais imersos nesse processo, de modo a garantir uma construção coletiva (Lück, 2010). Os docentes ressaltam que a autonomia em relação à SME $(n=2)$ e o diálogo colaborativo em decorrência das normatizações estabelecidas para as instituições são aspectos importantes, tendo em vista a contribuição e a realidade vivenciada por cada instituição de ensino.

A rede de interesses 2, figura 2, contempla a discussão realizada sob a ótica discente acerca dos pontos para o aprimoramento dessas ações e práticas educativas no contexto de organização e espaço escolar. 
Figura 2 -

Aspectos que necessitam de aprimoramento conforme os docentes entrevistados.

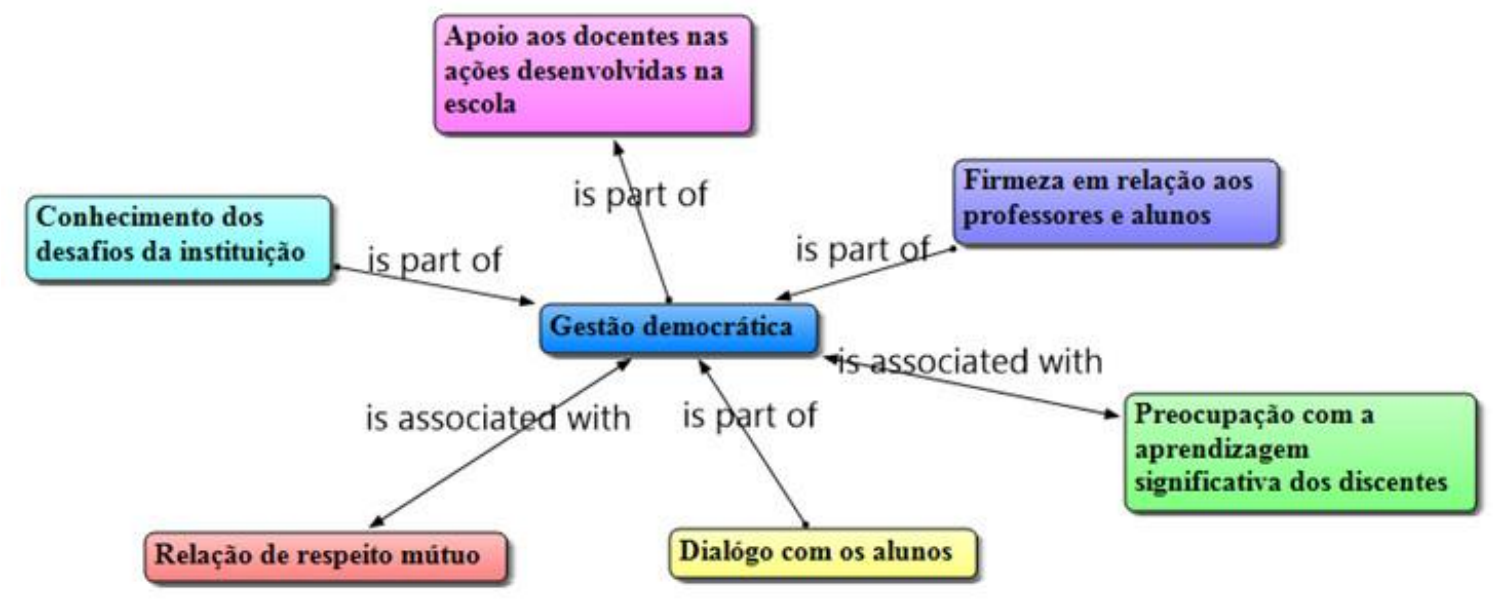

Fonte: Elaboração própria.

\section{Considerações finais}

Em face da análise realizada observou-se que o planejamento é uma das estratégias adotadas para a organização das ações e tomadas de decisão na escola, entretanto, essas ações são engessadas. Diante disso, os docentes desejam que o planejamento e as reuniões tenham um tempo maior de duração para que possam participar e contribuir nas tomadas de decisão. A manifestação do docente A1 da escola $A$, a seguir, retrata bem esse processo que ocorre nas instituições de ensino pesquisadas:

O grupo de professores, às vezes, precisa de uma reunião, e não é possível sequer reservar uma aula para isso e colocar os alunos numa atividade diferente para que os professores possam se reunir ou mesmo avisar antecipadamente que os alunos vão sair mais cedo.

O engessamento das ações deve ser revisto, de sorte a facilitar a participação dos docentes nos encaminhamentos gerados na escola. Os compromissos devem ser refletidos por todos que compõem a instituição, com o intuito de amadurecimento das ideias, a fim de gerar sentido aos desdobramentos e desafios oriundos das unidades escolares, revendo estratégias e soluções atentas ao contexto em que as instituições estão inseridas.

Em face dos recursos insuficientes, visualizou-se, conforme a análise geral das manifestações dos docentes, que falta uma estrutura básica que atenda às necessidades e ao desenvolvimento pedagógico dos alunos, bem como se constatou ser necessária a melhoria dos espaços em que as escolas estão localizadas para a promoção de ações.

Por meio da manifestação dos docentes verificou-se que esse processo de participação deve ser aprimorado, por envolver a abertura da comunidade nas tomadas de decisão e nas dificuldades que as escolas possam vivenciar. 
A comunidade deve estar presente na unidade escolar e consciente do papel que desempenha. Papel esse que vai além dos compromissos institucionais organizados sistematicamente pelos gestores por meio de reuniões e eventos que ocorrem nas instituições de ensino, mas participar ativamente na busca por melhorias e nas tomadas de decisões que são estabelecidas nas instituições.

Dessa forma, a avaliação visa a contribuir para novas tomadas de decisão, envolvendo a participação dos sujeitos que integram a escola, evidenciando, assim, uma gestão participativa e atenta às práticas por meio do diálogo, bem como a integração dessas falas para melhorias nas instituições de ensino. Segundo Vianna (2000, p. 76), "a avaliação não terá um crédito relevante se tudo aquilo que o avaliador estabeleceu e aprendeu não for incorporado ao conhecimento de diferentes públicos: alunos, professores, pais, administradores, burocratas e a todos os cidadãos interessados em problemas educacionais".

Em face da análise realizada verificou-se que o diálogo é concebido pelos gestores entrevistados como um aspecto importante, entretanto, conforme a docente B1 da escola B, esse processo deve ser refletido e aprimorado, tendo em vista o engajamento de professores com a participação ativa: "Saber realmente como eles participam a gente não sabe. A gente não é muito incluída nessa parte".

O trabalho atrelado à formação docente deve, pois, considerar os anseios dos docentes e discentes, além do contexto em que as práticas são conduzidas nas escolas. Essa avaliação apresenta-se como relevante e contínua, que visa à realidade e necessidades dos estudantes e à dialogicidade nos encaminhamentos gerados e praticados na escola.

\section{Referências}

ALVES, Nilda; VILLARDI, Raquel (org.). Múltiplas leituras da nova LDB: Lei de Diretrizes e Bases da Educação. Rio de Janeiro: Qualitymark Dunya, 1997.

ANDRADE, Rosamaria Calaes de. A gestão da escola. Porto Alegre: Artmed, 2004.

ANDRIOLA, Wagner Bandeira. Múltiplos olhares em torno da educação. Fortaleza: UFC, 2005.

ARAÚJO, Karlane Holanda. Os efeitos do Programa Escola Nota 10 nos processos pedagógicos das escolas premiadas de Sobral e das apoiadas de Caucaia no ano de 2009. 2016. 184f. Dissertação (mestrado em Educação). Programa de Pós-Graduação em Educação, Universidade Federal do Ceará.

BARROSO, João. Relatório da disciplina: teoria das organizações e da administração educacional. Lisboa: Universidade de Lisboa, 2001.

DEMO, Pedro. A nova LDB: ranços e avanços. Campinas: Papirus, 1997.

LIBÂNEO, José Carlos; OLIVEIRA, João Ferreira de; TOSCHI, Mirza Seabra. Educação escolar: políticas, estrutura e organização. São Paulo: Cortez, 2012.

LÜCK, Heloísa. Concepções e processos democráticos de gestão educacional. Petrópolis: Vozes, 2012.

LÜCK, Heloísa. Perspectivas da gestão escolar e implicações quanto à formação de seus gestores. Em Aberto, Brasília, n. 72, 2000, p. 11-34. 
LUCKESI, Cipriano. Avaliação de programas educacionais em organizações: contrato de avaliação e indicadores de aproveitamento. Fortaleza: UFC, 2005.

OLIVEIRA, Inês Barbosa de; GONDRA, José Gonçalves. Centralização, omissão e dubiedades na organização da educação nacional in: ALVES, Nina; VILLARDI, Raquel (org.). Múltiplas leituras da nova LDB: Lei de Diretrizes e Bases da Educação. Rio de Janeiro: Qualitymark Dunya, 1997, p. 67-84.

PERRENOUD, Philippe. Avaliação. Porto Alegre: Artmed, 1999.

PORTELA, Adélia Luiza; ATTA, Dilza Maria Andrade. A gestão da educação escolar hoje: o desafio pedagógico. In: LUZ, Ana Maria de Carvalho; PORTELA, Adélia Luiza (org.). Gestão educacional e qualidade social da educação. Salvador: UFBA, 2007, p. 9-35.

SAVIANI, Dermeval. Sistema de educação: subsídios para a Conferência Nacional de Educação (Conae). Brasília: Inep, 2010.

VIANNA, Heraldo Marelim. Avaliação educacional: teoria, planejamento e modelos. São Paulo: Ibrasa, 2000.

VIANNA, Heraldo Marelim. Testes em educação. São Paulo: Ibrasa, 1976.

VIEIRA, Sofia Lerche. Políticas e gestão da educação básica: revisitando conceitos simples. Revista Brasileira de Política e Administração da Educação, Goiânia, v. 23, n. 1, 2007, p. 53-54.

WEBER, Max. Ciência e política: duas vocações. São Paulo: Martin Claret, 2001.

Marcos Antonio Martins Lima é professor associado na Universidade Federal do Ceará, economista, mestre em Administração, doutor em Educação e pósdoutorando em Gestão. Coordenador do Grupo de Pesquisa em Avaliação \& Gestão Educacional vinculado aos Programas de Pós-graduação em Educação e Administração e Controladoria da Universidade Federal do Ceará.

Endereço: Rua Dr. Gilberto Studart, 1290/902 - 60192-095 - Fortaleza - CE - Brasil. E-mail: marcos.a.lima@terra.com.br.

Denize de Melo Silva é professora na rede pública municipal de Fortaleza/CE. Pedagoga pela Universidade Federal do Ceará, mestre em Educação Brasileira, pesquisadora e colaboradora do Grupo de Pesquisa em Avaliação \& Gestão Educacional vinculado ao Programa de Pós-graduação em Educação da Universidade Federal do Ceará.

Endereço: Rua José Vilar, 495/68 - 60125-000 - Fortaleza - CE - Brasil.

E-mail: denisemellopedagoga@gmail.com.

Ana Paula Vasconcelos de Oliveira Tahim é professora na Faculdade Cearense, pedagoga, especialista em Coordenação Pedagógica, mestre em Educação Brasileira pela Universidade Federal do Ceará, estudante do curso de doutorado em Educação Brasileira pela Universidade Federal do Ceará. Pesquisadora e colaboradora do Grupo de Pesquisa em Avaliação \& Gestão Educacional.

Endereço: Rua Mauro Freire, 300/902A - 60824-030 - Fortaleza - CE - Brasil.

E-mail: anapaula tahim@yahoo.com.br.

Recebido em 18 de outubro de 2016.

Aceito em 19 de abril de 2017. 